\title{
TU/e EN⿴HONE

\section{Properties of leaky waves supported by grounded dielectric super-layers and implications on the design of reflector feeds}

\section{Citation for published version (APA):}

Neto, A., Llombart, N., Gerini, G., Bonnedal, M., \& de Maagt, P. J. I. (2007). Properties of leaky waves supported by grounded dielectric super-layers and implications on the design of reflector feeds. In Proceedings of IEEE Antennas and Propagation Society International Symposium, Honolulu, HI , 9-15 June 2007 (pp. 5660-5663). Institute of Electrical and Electronics Engineers. https://doi.org/10.1109/APS.2007.4396834

DOI:

10.1109/APS.2007.4396834

Document status and date:

Published: 01/01/2007

\section{Document Version:}

Publisher's PDF, also known as Version of Record (includes final page, issue and volume numbers)

\section{Please check the document version of this publication:}

- A submitted manuscript is the version of the article upon submission and before peer-review. There can be important differences between the submitted version and the official published version of record. People interested in the research are advised to contact the author for the final version of the publication, or visit the $\mathrm{DOI}$ to the publisher's website.

- The final author version and the galley proof are versions of the publication after peer review.

- The final published version features the final layout of the paper including the volume, issue and page numbers.

Link to publication

\section{General rights}

Copyright and moral rights for the publications made accessible in the public portal are retained by the authors and/or other copyright owners and it is a condition of accessing publications that users recognise and abide by the legal requirements associated with these rights.

- Users may download and print one copy of any publication from the public portal for the purpose of private study or research.

- You may not further distribute the material or use it for any profit-making activity or commercial gain

- You may freely distribute the URL identifying the publication in the public portal.

If the publication is distributed under the terms of Article 25fa of the Dutch Copyright Act, indicated by the "Taverne" license above, please follow below link for the End User Agreement:

www.tue.nl/taverne

Take down policy

If you believe that this document breaches copyright please contact us at:

openaccess@tue.nl

providing details and we will investigate your claim. 


\title{
Properties of Leaky Waves Supported by Grounded Dielectric Super-Layers and Implications on the Design of Reflector Feeds
}

\author{
A. Neto ${ }^{1}$, N. Llombart ${ }^{1}$, G. Gerini ${ }^{1}$, M. Bonnedal ${ }^{2}$, and P. De Maagt ${ }^{3}$ \\ ${ }^{1}$ TNO Defence, Security and Safety, Den Haag, The Netherlands \\ ${ }^{2}$ Saab Space, Gothenburg, Sweden \\ ${ }^{3}$ ESTEC, European Space Agency, Noordwijk, The Netherlands
}

\section{Introduction}

When the distance between a dielectric superlayer and a ground plane is about half of a free space wavelength, leaky waves can propagate between the sandwiched area. So far the main application of these leaky waves has been the enhancement of the broadside directivity of a single antenna. Originally the properties of these reinforcement mechanisms were described in simple terms by G. Trentin [1]. More recent investigations [2] have clarified the basic mechanisms of leaky waves. Their properties are most efficiently described by the poles of the pertinent spectral domain Green's function. Previously the poles had to be derived numerically and the available approximate expressions were valid only for limited ranges of frequencies or for very high values of the dielectric constants (to the limit of being impractical). In [3] a simple procedure to obtain analytical approximations of the leaky wave poles extending the ranges of the approximations was provided. In the present contribution, starting from the analytically derived expressions of the poles and the pertinent residues, all important parameters for a reflector waveguide feed that makes positive use of these leaky waves are studied.

\section{Polar Representation of the Radiated Field}

The radiation patterns can be expressed as superposition of a few leaky wave patterns and their shape can be optimized to meet some predefined targets that are suitable for efficiently exciting the reflector. The electric or magnetic fields radiated by an elementary magnetic current in the presence of the multilayered dielectric structure and of the ground plane are most compactly expressed as inverse Fourier transforms of the spectral Green's Functions. It is well known that when the observation point is at large distance from the dielectric stratifications, a simple uniform asymptotic evaluation of the field can be performed. The propagation constant of each leaky wave pole $k_{l w}=k_{0}\left(\sin \theta_{l w}+j \delta_{l w}\right)$ is defined by the zeros of the denominators of the potential functions $V_{T E}, V_{T M}$. Since the voltages can be expressed as $V_{T E / T M}\left(k_{\rho}\right)=\frac{N\left(k_{\rho}\right)}{D\left(k_{\rho}\right)}$, the residues at the poles locations, $\operatorname{Res}\left(V_{T E / T M}\right)\left(k_{l w}\right)$ can be calculated as $\frac{N\left(k_{l w}\right)}{D^{\prime}\left(k_{l w}\right)}$ where the prime denotes derivation with respect to $k_{\rho}$. The explicit form of this derivative will depend on the specific stratification. However in all cases the denominator $D\left(k_{\rho}\right)$ includes the

functions $k_{z 0}=\sqrt{k_{0}^{2}-k_{\rho}^{2}}$ and $k_{z 1}=\sqrt{\epsilon_{r} k_{0}^{2}-k_{\rho}^{2}}$. Thus the derivatives $D^{\prime}\left(k_{l w}\right)$ are explicitly proportional to $k_{l w}=k_{0}\left(\sin \theta_{l w}+j \delta_{l w}\right)$. As a consequence the magnitudes of the residues are higher for smaller pointing angles when $\delta_{l w}$, the at- 
tenuation constant, is very small. The potentials can be directly approximated in the surrounding of the $p-t h$ pole, namely $k_{l w p}$, using the residue theory as $V_{T E / T M}\left(k_{\rho}\right)_{\mid k_{\rho} \approx k_{l w p}} \approx V_{T E / T M}^{l w p}\left(k_{\rho}\right)=\frac{2 k_{l w p}}{k_{\rho}^{2}-k_{l w p}^{2}} \operatorname{Res}\left(V_{T E / T M}\right)\left(k_{l w p}\right)$. The functions $F_{T E / T M}\left(k_{\rho}\right)=V_{T E / T M}\left(k_{\rho}\right)-\sum_{p=1}^{N_{p}}\left(V_{T E / T M}^{l w p}\left(k_{\rho}\right)\right)$ are analytic in the entire domain $\left(\left|k_{\rho}\right|<k_{0}\right)$. This implies that $F_{T E / T M}$ can be well approximated by a power series expansions around $\left(k_{\rho}=0\right)$. Retaining only the first term of such series, $F_{T E / T M}(0)$, a convenient expansion for the original potentials is found to be:

$$
V_{T E / T M}\left(k_{\rho}\right) \approx F_{T E / T M}(0)+\sum_{p=1}^{N_{p}}\left(V_{T E / T M}^{l w p}\left(k_{\rho}\right)\right)
$$

The convenience of this representation, even considering that the starting point were analytically known potentials, is that the contribution of each term to the far field pattern can be isolated as associated to a specific design parameter. In fact a pole is dominant in a certain angular domain of the pattern, around $\theta_{l w}$ when it has a small imaginary part. As an example one can try to obtain a pattern shaped as $\sec ^{4}(\theta / 2)$ that will provide the maximum aperture efficiency from a reflector. The geometry of the structure is described in Fig.1(a). Both $\mathrm{E}$ and $\mathrm{H}$ planes patterns of the example are shown in Fig.1. The graphs compare the results achieved retaining the complete GF asymptotic evaluation and its approximation, eq. (1).

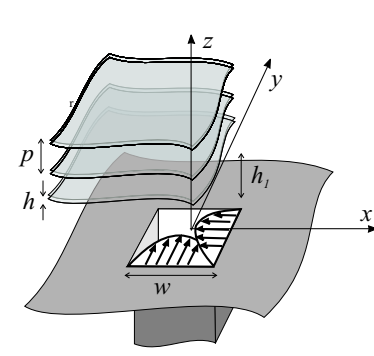

(a)

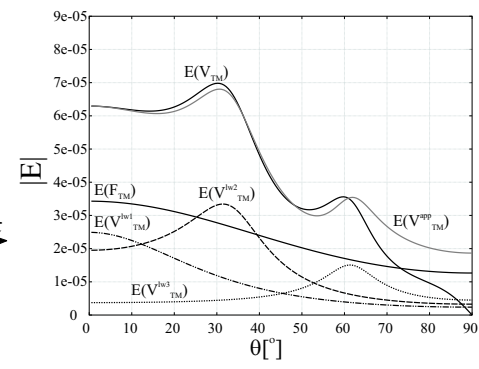

(b)

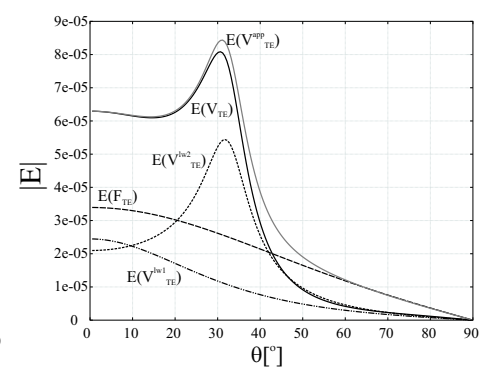

(c)

Figure 1: (a) Square metallic waveguide in a infinitely extended ground plane covered by a period arrangement of infinite dielectric layers (b) E-plane and (c) H-plane radiation patterns

\section{Bandwidth Limits}

In order to quantify the impact of the dielectric super-layers in the input impedance BW Fig. 2(a) presents the admittance of a square waveguide in presence of the stratification $Y$ and in free space $Y^{f s}$ as a function of the frequency. The amplitude of the oscillations is proportional to the amplitude of the intensity of the excitation of the leaky waves. This amplitude is quantified by the value of the pertinent residue at the dominant pole: $\operatorname{Res}\left(I_{T E / T M}\right)\left(k_{l w p}\right) \propto 1 / \sin \theta_{l w p}$. Correspondingly, the input admittance is varying function of the frequency, with stronger oscillations for 


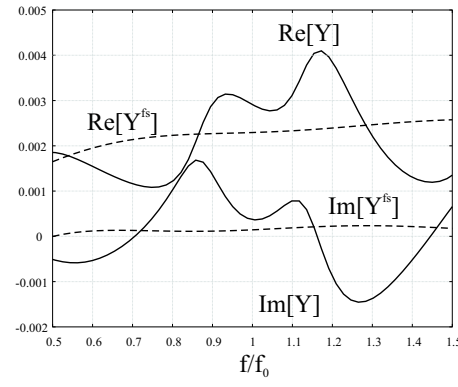

(a)

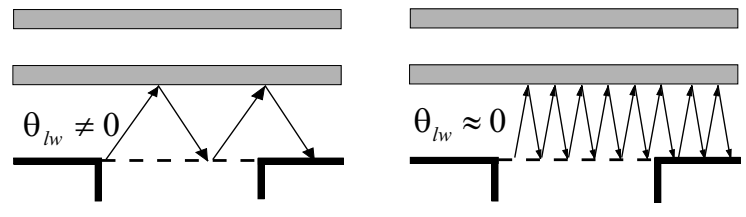

(b)

Figure 2: (a) Input admittance in the presence of a dielectric super-structure and in free space. (b) Ray picture associated to two configurations corresponding to a leaky wave radiating toward a direction clearly different or close to broadside $\left(\theta_{l w} \approx 0\right)$.

broadside pointing configurations. This property is common to all designs that use Fabry Perot like structures. The enhancement of broadside directivity is achieved at the expense of working BW. The BW behavior can be intuitively understood by observing that when the leaky wave radiates toward broadside more reflections from the dielectric slabs will be directly coupled into the wave-guides, than when the leaky wave is pointing toward larger angles, see Fig.2(b).

\section{Mutual Coupling Issues}

In the case of a focal plane waveguide array, the mutual coupling parameter can also be estimated analytically starting from the knowledge of the leaky wave poles and their residues. In fact, the mutual admittance, and correspondingly the mutual coupling, has two contributions. One associated to the space wave and one associated to the leaky waves propagating in the structure. When the waveguides have widths in the order of a free space wavelength, the space wave launched in directions tangent to the ground plane is very small, thus also the corresponding space wave coupling is very small. In this situation the mutual admittance is dominated by the leaky wave contribution: $Y \approx Y_{l w}$. It is apparent that for smaller values of $k_{l w}$ associated to large dielectric constants, the leaky wave contribution to the mutual admittance is larger. This is confirmed by looking to the absolute value of $Y_{l w}^{H / E}$ in Fig. 3(a) and to the $S_{12}$ in (b) for the same cases. The power coupled into the neighboring wave-guides has two main implications in a multi beam array scenario depending on the loading of the neighboring waveguides. If all the non active apertures are closed in perfect matched loads and depending on the mutual coupling level, some power is dissipated in the loads (e.g. $S_{i j} \approx-15 \mathrm{~dB}$ implies $-0.91 \mathrm{~dB}$ of loss in 4 neighboring waveguides). Moreover there will always be a directly scattered contribution to the pattern with the same level of power that will reduce the directivity in the array environments with respect to the isolated waveguide. That is because the distance between the array elements is such that the scattered field from the neighboring waveguides contributes almost out of phase with respect to the central element. This will always be the case when one tries to pack the ele- 


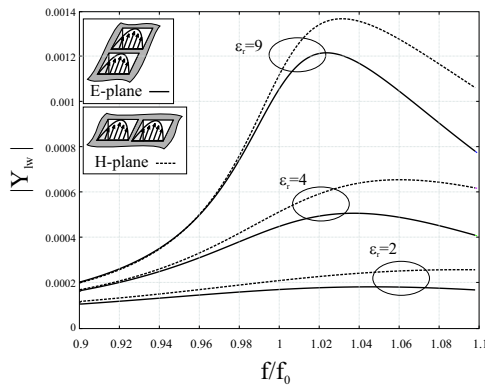

(a)

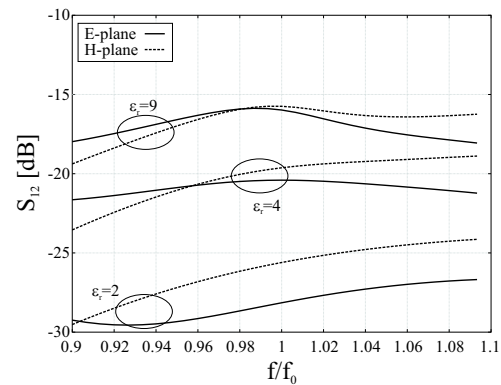

(b)

Figure 3: (a) Leaky wave admittances between two apertures in both $\mathrm{E}$ and $\mathrm{H}$ planes (b) $T E_{10}$ mutual coupling of the same cases calculated full-wave.

ments as close as possible one to the other. The leaky waves mostly contributing to the mutual coupling do not allow, $e^{-j k_{L W} d}$, for a significant phase difference over a small distance: i.e. $R e\left[k_{l w}\right] d \approx 0$. This problem would be much more important if $\theta_{l w} \rightarrow 0$ and correspondingly the higher mutual couplings could have an even more destructive impact. If the loads are intentionally rendered reactive, no power will be

dissipated and a reflected field will contribute to the radiation pattern. The reflected field could be designed to cancel out the scattered field, eventually implementing an equivalent ground plane.

\section{Conclusions}

The design strategy that uses dielectric super-layers with neighboring wave-guides closed in matched loads constitutes a worst case scenario as far as the performance enhancement is concerned and finds applicability in radiometric imaging arrays. On the other side the design strategy that uses dielectric super-layers with neighboring wave-guides closed in properly tuned reactive loads can be seen as best case scenario representative of a multi beam system for a telecommunication satellite with independent channels.

\section{References}

[1] G.V. Trentini, "Partially reflecting sheet arrays", IEEE Trans. on AP, Vol.4, Iss.4, Oct. 1956, pp. 666- 671

[2] D. R.Jackson, A. A. Oliner, "A Leaky-Wave Analysis of the High-Gain Printed Antenna Configuration", IEEE Trans. on AP, Vol. 36, no. 7, pp. 905-909, July 1988 .

[3] A. Neto, N. Llombart, "Wide Band Localization of the Dominant Leaky Wave Poles in Dielectric Covered Antennas", IEEE AWPL 2006. 